\title{
VARIOUS ANALYTICAL MODELS FOR SUPERCAPACITORS: A MATHEMATICAL STUDY
}

\author{
Prasad R., Mehta U., Kothari K. \\ School of Engineering and Physics, The University of the South Pacific, Laucala campus, Suva, Fiji
}

\begin{abstract}
Supercapacitors (SCs) are used extensively in high-power potential energy applications like renewable energy systems, electric vehicles, power electronics, and many other industrial applications. This is due to SCs containing high-power density and the ability to respond spontaneously with fast charging and discharging demands. Advancements in material and fabrication techniques have induced a scope for research to improve the application of SCs. Many researchers have studied various SC properties and their effects on energy storage and management performance. In this paper, various fractional calculus-based SC models are summarized, with emphasis on analytical studies from derived classical SC models. Study prevails such parameterized resistorcapacitor networks have simplified the representation of electrical behavior of SCs to deal with the complicated internal structure. Fractional calculus has been used to develop SC models with the aim of understanding their complicated structure. Finally, the properties of different SC models utilized by various researchers to understand the behavior of SCs are listed using an equivalent circuit.
\end{abstract}

Keywords: Supercapacitors; Mathematical model; Fractional order; Energy storage.

\section{Introduction}

A supercapacitor (SC), also known as an ultracapacitor or electric double-layer capacitor (EDLC), is a type of energy storage component that has a large capacitance with quick charge and discharge times [1]. SCs store energy in the form of electrical energy through the use of ions [2]. This is in contrast to batteries and conventional capacitors; however, SCs are a combination of both [3]. The structure of SCs is similar to that of a battery, which uses an electrolyte solution and electrodes, but the method of storing energy is similar to conventional capacitors, which use electrostatic force. Moreover, the mechanism of storing energy is through the use of ions in an electrolyte solution but without any chemical reaction taking place at the electrode. The elec-

* Corresponding authors: Utkal Mehta

E-mail: utkal.mehta@usp.ac.fj

is Peer review under responsibility of Tomsk Polytechnic University. https://doi.org/10.18799/24056537/2020/1/218/ trodes are polarized, and charge accumulation in an electrolyte double layer is used to store the energy electrostatically in an SC [4]. SCs utilize a higher surface area, which is greatly attributed to the porouslike structure of electrodes and thinner dielectrics to achieve greater capacitance. Because of this, SCs have greater power densities, typically 10 times that of a battery and 100 times greater than most conventional capacitors [4]. Longevity, in terms of the life cycle, is another key benefit of SCs over batteries, but the longevity of SCs is less than conventional capacitors; hence, SC bridges the gap between the two [4$6]$.

In the past decade, significant developments in SC technology have increased its applications in terms of energy storage and power delivery aspects. SCs fulfill a key role as an energy storage device where there is need to store or supply short energy pulses for a short duration. Such storage and supply applications include electric hybrid cars [7] (e.g., 
regenerative braking), renewable energy systems $[8,9]$, biomedical sensors [8], and other electronic products. Large-scale SCs are used as power quality regulators in electrical grids as well [9].

It is normal practice to model the dynamics of a system in order to understand the system and design better control systems. Calculus is commonly used to mathematically model systems and mainly derives integer-order transfer functions. However, there are phenomena for which ordinary integer-based calculus does not satisfy the requirements of modeling the characteristics. Recent studies have suggested that SCs are an example of such a system and seem to exhibit fractional-order calculus-based characteristics [10-13]. Modeling of these systems requires the use of more sophisticated techniques from which one can extrapolate their actual behavior for control and management purposes.

In this paper, a brief survey is conducted on SC models with special emphasis on the use of fractional calculus theory. This paper aims to summarize the recent representation of fractional-order models to capture the behavior of SCs and to unlock more opportunities in system identification and control.

\section{SC structure and electrochemical behavior}

In 1853, Helmholtz first discovered the doublelayer phenomenon, which scientists went on to study to store electrical charges [14, 15]. These studies led to a patent filing in 1957 by Becker from General Electric Company for a low-voltage SC [16]. Since then, three different types of SC were invented that differ in terms of charge storage: the EDLC, the pseudocapacitor (PC), and the hybrid capacitor (HC) [17]. Fig. 1 shows the layout of these SCs. EDLCs are based on a non-faradaic process and do not involve the breakage or formation of any chemical bonds. PCs are based on a faradaic redox reaction process and the transfer of charges between the electrode and electrolyte [18-20]. HCs, as the name implies, are a combination of both EDLCs and the PCs [17].

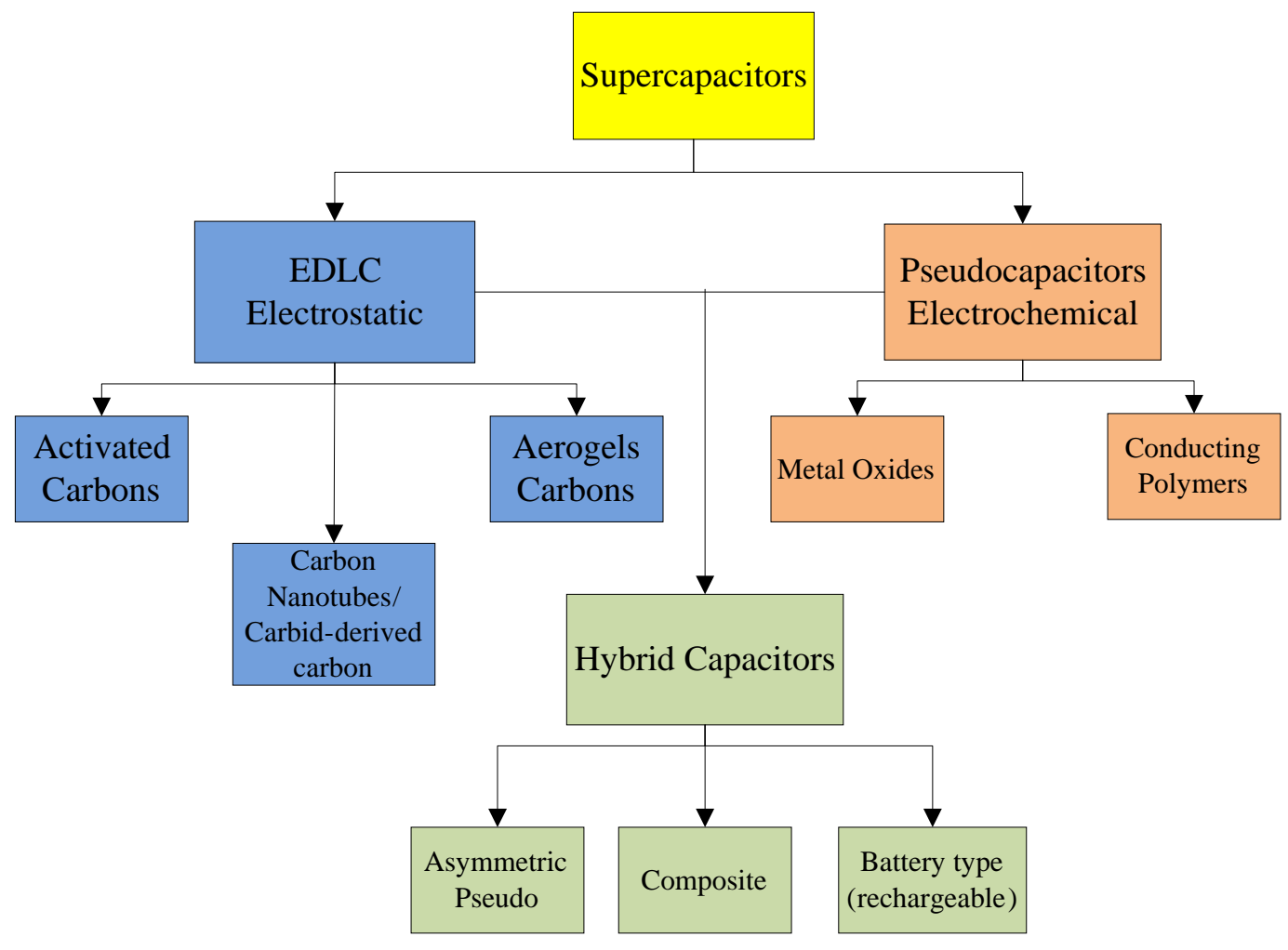

Fig. 1. Supercapacitor family

The structure of an SC consists of electrodes and an electrolyte solution [21, 22]. The electrodes have a porous-like structure that enables the electrolyte solution to have contact with a higher surface area, giving it a higher capacity to hold charges than regular capacitors. Unlike batteries, there is no contact between the electrodes and the electrolyte solution, omitting any chemical reaction [4]. A membrane separator is used to avoid any electrical short circuit between the two electrodes [23]. The structure of an SC is shown in Fig. 2. 
SCs operate similar to a normal capacitor because there is separation between the electrodes and the electrolyte solution. The charge arrangement is the only process that takes place during the charge or discharge phase of the capacitor. The separation of the electrode and electrolyte causes the charge to be stored through electrostatic forces. This causes a charge to build up a double layer around the object, giving rise to the term EDLC [21, 4]. More specifically, it can be treated as a series of two connected capacitors. The two capacitors consist of the capacitance of the stern layer and the capacitance of the diffusion layer. The former arises from the electrostatic charge attraction at the surface, and the latter is the capacitance formed by the free ions in the electrolyte that move about freely due to the thermal and electrostatic attraction [23-27]. Because of this, double-layer formation and relaxation occur more quickly when a voltage difference is applied. The voltage rating of the $\mathrm{SC}$ is mostly dependent on the decomposition of the electrolyte solution. Other factors contributing to the working voltage of the capacitor are the operating temperature, current density, and required life cycle $[4,28]$.

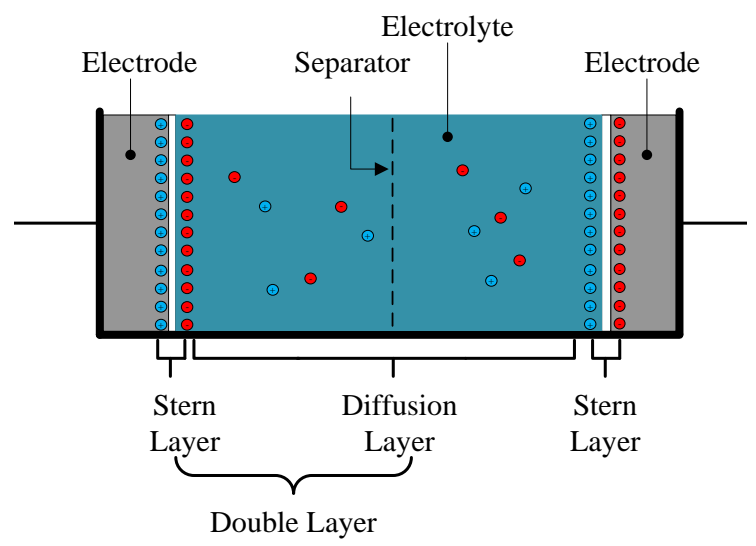

Fig. 2. Supercapacitor internal structure

\section{SC fractional-order modeling}

To capture the nonlinear dynamics of a physical $\mathrm{SC}$, fractional-order modeling is preferred and has evolved over the past decade. Fractional-order models reflect the actual behavior better than integer-based models. To demonstrate this, Fig. 3 shows the ideal cyclic voltammetry behavior of ideal, resistive, and physical capacitors. Because of the more complicated structure of SCs and use of ion movements (diffusion) to store energy, its description requires a more complicated method. Moreover, this type of diffusion, as well as suspension-like granular substances in disordered solids, can only be factored using fractional-order equations. Researchers have shown how fractionalorder models can demonstrate this behavior using charging/discharging of a capacitor with various types of input conditions. Considering the importance of this subject, this paper will first look at the different types of analytical models that exist to date that have been created on the basis of fractional calculus.

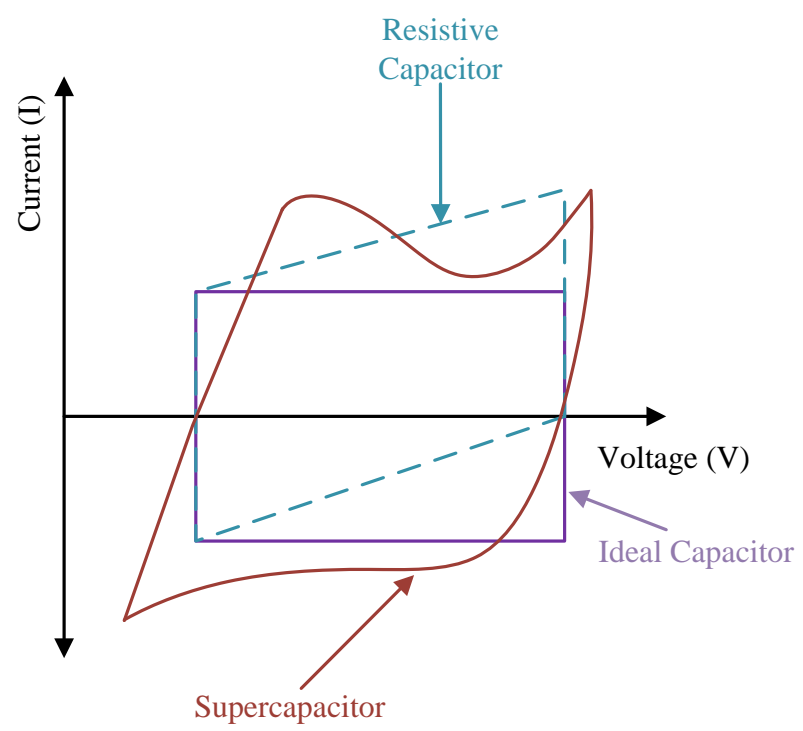

Fig. 3. Ideal cyclic voltammetry behavior of capacitors

\subsection{Simple resistor-capacitor model}

A simple resistor-capacitor ( $\mathrm{RC}$ ) model based on the behavior of a porous electrode model has been explored in [29-31] and is shown in Fig. 4. This model employs a parameterized RC network to imitate the electrical properties of SCs. It compromises a series resistor, $R_{S}$, and a constant phase element $(\mathrm{CPE})$ that is mostly a fractional capacitor with a real order, $\alpha$, that ranges from 0 to 1 . The impedance of $\mathrm{CPE}$ can be written as $Z_{C P E 1}=1 /\left(C s^{\alpha}\right)$ in Laplacian form (or in the s-domain). In [29], a charging circuit with a step voltage input was developed, as illustrated in Fig. 4. The total impedance, $Z_{S C 1}(s)$, expression for such a porous model as Fig. 4 can be written simply as

$Z_{S C 1}(s)=R_{s}+\frac{1}{C s^{\alpha}}$

The transfer function for this charging circuit with initial zero conditions can be given by

$V_{o}(s)=\frac{V_{i n}(s) \frac{1}{C\left(R+R_{s}\right)}+V_{i n}(s) s^{\alpha} \frac{R_{s}}{R+R_{s}}}{s^{\alpha}+\frac{1}{C\left(R+R_{s}\right)}}$ 
given that the two-parameter Mittag-Leffler function is defined by

$$
E_{\alpha, \beta}(x)=\sum_{k=0}^{\infty} \frac{x^{k}}{\Gamma(\alpha k+\beta)},
$$

where the gamma function $(\Gamma)$ is defined as

$$
\Gamma(x)=\int_{0}^{\infty} e^{-t} t^{x-1} d t, \quad x \in R^{+} .
$$

The time domain translation of equation (2) in terms of equation (3) for a step response of input voltage amplitude $\left(V_{c c}\right)$ is

$$
v_{o}(t)=V_{c c}\left[\begin{array}{l}
\frac{t^{\alpha}}{C\left(R+R_{s}\right)} E_{\alpha, \alpha+1}\left(\frac{-t^{\alpha}}{C\left(R+R_{s}\right)}\right)+ \\
+\frac{R_{s}}{R+R_{s}} E_{\alpha, 1}\left(\frac{-t^{\alpha}}{C\left(R+R_{s}\right)}\right)
\end{array}\right] .
$$

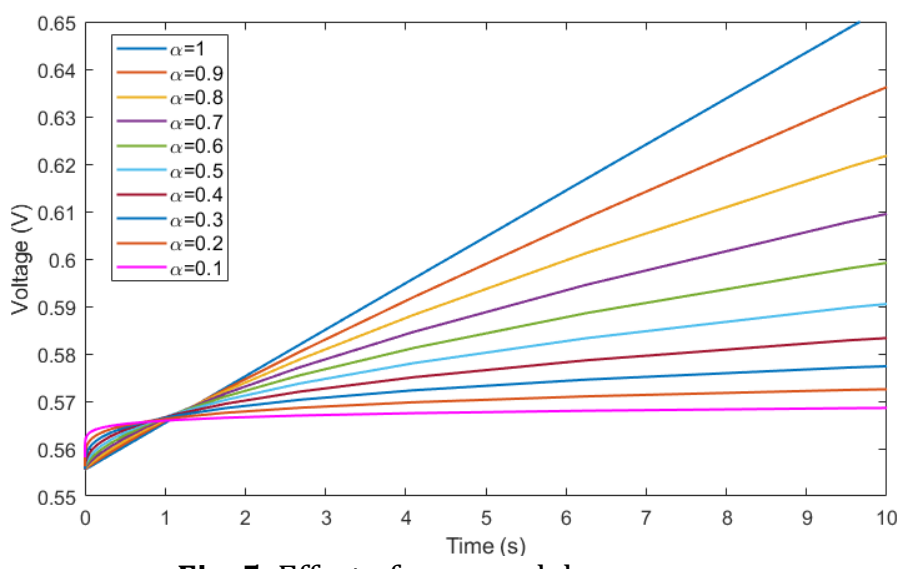

Fig. 5. Effect of $\alpha$ on model responses

A MATLAB simulation of equation (5) is illustrated in Fig. 5. The simulation was conducted for $\alpha$, ranging from 0.1 to 1 at an interval of 0.1 . The data were simulated for $C=2 \mathrm{~F}, R_{s}=25 \Omega, R=200 \Omega$, and $V_{c c}=5 \mathrm{~V}$. It can be observed that lower $\alpha$ values represent a slow charging behavior, whereas higher $\alpha$ values indicate faster charging. The simulation also depicts the flexibility in modeling using fractional order $\alpha$.

The model in equation (1) has been widely used in the literature as it is simple and fits well with the experimental data at both high and low frequencies. Frequencies between the range of $10 \mathrm{mHz}$ and $1,000 \mathrm{~Hz}$ were utilized to model the impedance, where $\alpha \approx 1$ for the frequency range of $50-215 \mathrm{mHz}$ and $\alpha \approx 0.5$ for $450 \mathrm{mHz}$ to $100 \mathrm{~Hz}[30,32]$. The model was also used in a study for the step response of commercial SCs [29]. In [33], the calculation of capacitance, power, and energy of SCs was shown on the basis of constant current step and linear volt- age inputs. The same model was also used in [34] to study the effect of changing selected parameters of SCs on the output terminal voltage when charging and discharging. However, in [35], the author presented a similar model circuit but based on a subdiffusion equation. This proposed model had a CPE impedance of $Z_{C P E 2}=\left(\sqrt{1+T s^{\alpha}}\right) /\left(C s^{\alpha}\right)$, where $T$ is the capacitive time constant. The model based on $Z_{C P E 2}$ can be written as

$Z_{S C 2}(s)=R_{s}+\frac{\sqrt{1+T s^{\alpha}}}{C s^{\alpha}}$.

Another model expression is presented in [36] based on the constant phase transfer function $Z_{C P E 3}=\frac{(T s+1)^{\alpha}}{C s}$ to describe the RC model more accurately. This presented the transfer function as

$Z_{S C 3}(s)=R_{s}+\frac{(T s+1)^{\alpha}}{C s}$.

Suppose the confluent hypergeometric function is defined as

$f(b, c, x)=\sum_{n=0}^{\infty} \frac{(b)_{n}}{(c)_{n}} \frac{x^{n}}{n !},-\infty<x<\infty$,

where $(b)_{n}$ and $(c)_{n}$ are the Pochhammer symbols, defined by

$(g)_{n}=\frac{\Gamma(g+n)}{\Gamma(g)}, n=0,1,2,3,4 \ldots \ldots$

Then the time domain output voltage from the RC transfer function in equation (7) with a unit step current input can be given as

$v_{o}(t)=\frac{T^{\alpha}}{C} e^{-\frac{t}{T}} \frac{t^{1-\alpha}}{\Gamma(2-\alpha)} f\left(2,2-\alpha, \frac{t}{T}\right)$.

Moreover, in [37], a similar model, but with CPE impedance used, is presented as

$Z_{C P E 4}=R_{\omega} \frac{\operatorname{coth} \sqrt{R_{\omega} C s}}{\sqrt{R_{\omega} C s}}$,

where $R_{\omega}$ is the resistance that spans the Warburg region at $45^{\circ}$. At lower frequencies, the impedance of the CPE is estimated using

$\lim _{s \rightarrow 0} Z_{C P E 4}(s)=\frac{1}{C s}$,

and at higher frequency, equation (11) is estimated to be a fractional integrator of order 0.5 and is given as 
$\lim _{s \rightarrow \infty} Z_{C P E 4}(s)=\frac{\sqrt{R_{\omega} C}}{C s^{0.5}}$.

In general, the network structure of the SC in Fig. 4 is simple for circuit analysis and transfer function derivation, which explains its wide use in multiple studies. CPE impedance is the most altered variable in different studies to best capture the possible behavior of the SC.

\subsection{Poles and zeros model}

The RC model in equation (1) can be extended to incorporate zeros of order $\beta$, ranging from $0<\beta \leq 1$ rather than just having poles. The study in [32] shows that this can lead to a transfer function for the system to be

$Z_{S C}(s)=R_{s}+\frac{\left(1+\frac{s}{w_{0}}\right)^{\beta}}{C s^{\alpha}}$.

The advantage of using this form of the transfer function is to allow extraction of impedance parameters more appropriately when considering control diagrams like the Nyquist plot and the Bode diagram. This usually takes into account the changes in the phases at respective frequencies.

\subsection{Structural model}

The electrochemical process that takes place inside the SC is difficult to explain. Therefore, electrochemical elements are used to describe some of the processes together with a combination of capacitors and resistors that form a fractal array. In general, three constant phase or electrochemical elements are shown in the literature [38] as follows:

- Warburg impedance, $W(j \omega)$, is an element that describes the frequency depending on semi-infinite diffusion and the potential disturbance. This element is described mathematically as

$W(j \omega)=\frac{K}{\sqrt{j \omega}}$,

where $K$ is a constant.

- Bounded Warburg element, $O(j \omega)$, describes the linear diffusion that takes place in a homogenous layer of finite thickness. It is mathematically described as
$O(j \omega)=\frac{K \operatorname{coth}(B \sqrt{j \omega})}{\sqrt{j \omega}}$,

where $\mathrm{B}$ is the ratio of the diffusion layer thickness to the diffusion coefficient of the element.

- The Havriliak-Negami function-based element accounts for the asymmetric and broad nature of dielectric dispersion. Graphically, the broadness of the impedance curve is denoted by $\mu$, and the shape of the graph is determined by the parameter $\Phi$, where both of these parameters range from 0 to 1 . The parameter $\tau_{0}$ denotes the relaxation time. The function is defined as

$H(j \omega)=\frac{1}{j \omega\left(C_{0}-C_{\infty}\right)\left[1+\left(j \omega \tau_{0}\right)^{\mu}\right]^{\Phi}}$.

On the basis of the three aforementioned electrochemical elements, three models were used in [38] with structures shown in Fig. $6(a-c)$.

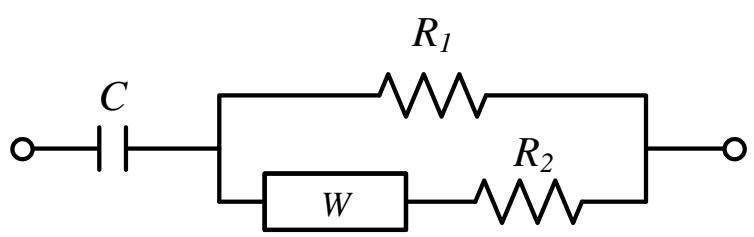

(a)

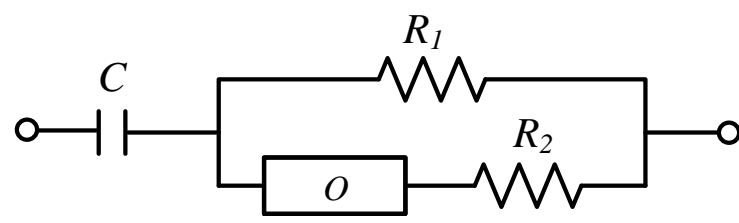

(b)

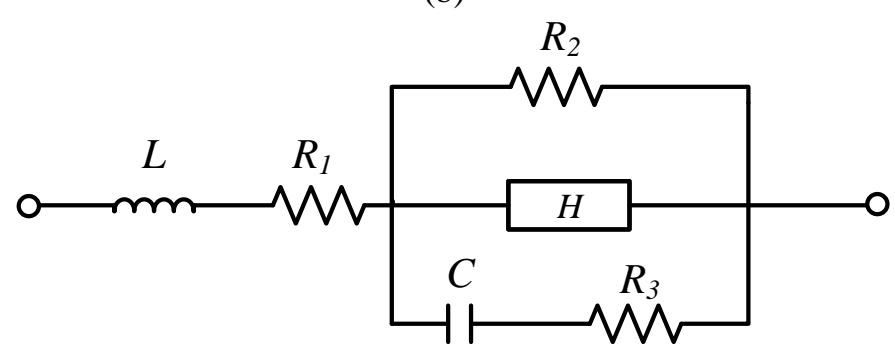

(c)

Fig. 6. Electrical circuit model for (a) Warburg, (b) bounded Warburg, and (c) Havriliak-Negami function-based models 


\subsection{RC parallel model}

After a charging or discharging phase of an SC, there is a diffusion process that results in thermal energy dissipation. The loss due to internal heat can be modeled as $R_{S}$. The leakage current due to parallel resistance can be considered with $R_{p}$. The model accounting for the thermal dissipation during charging and discharging of SCs is shown in Fig. 7. A similar model was proposed in [39] and analyzed using integer-order calculus. Later, this model was studied with fractional-order calculus to account for the self-discharge phenomenon more accurately [40]. The fractional-order transfer function was developed as

$G(s)=\frac{V(s)}{I(s)}=\left(k_{1} \frac{s^{\alpha}}{s^{\alpha}+a}+k_{2} \frac{s^{\alpha}}{s^{\alpha}+a}\right)$,

where

$k_{1}=R_{s}, k_{2}=\frac{R_{s}+R_{p}}{R_{p} C}, a=\frac{1}{R_{p} C}$.

$R_{s}$

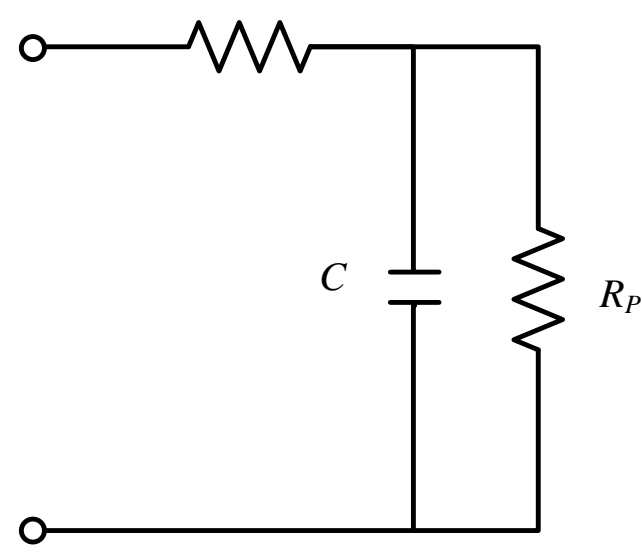

Fig. 7. Supercapacitor model accounting the thermal dissipation during charging/discharging

The transfer function expressed in equation (18) can be transformed to the time domain by using the Mittag-Leffler function. The generalized equation, assuming zero initial conditions, can be shown as

$$
\begin{gathered}
v(t)=\sum_{k=0}^{N}(i(k T)-i((k-1) T)) \times \\
\times\left[\begin{array}{c}
k_{1} \sum_{j=0}^{\infty} \frac{\left(-a(t-k T)^{\alpha}\right)^{j}}{\Gamma(\alpha j+1)}+ \\
+k_{2}(t-T)^{\alpha} \sum_{j=0}^{\infty} \frac{\left(-a(t-k T)^{\alpha}\right)^{j}}{\Gamma(\alpha j+\alpha+1)}
\end{array}\right],
\end{gathered}
$$

where $N T \leq t \leq(N+1) T$. This model was used in [40] to estimate the voltage at the terminals of the SC after a very long period. The same electrical circuit model was also used in [41] but was modeled mathematically using the Cole-Davidson (CD) and Cole-Cole (CC) relaxation models. The impedance transfer functions obtained using these theories are given by equations (21) and (22), respectively:

$$
\begin{aligned}
G_{C D}(s)= & \frac{\left(1+\frac{R_{s}}{R_{p}}\right) \cdot(1+s T)^{\beta}+s R_{s} C}{\frac{1}{R_{p}} \cdot(1+s T)^{\beta}+s C} ; \\
G_{C C}(s)= & \frac{\left(1+\frac{R_{s}}{R_{p}}\right)+s^{\alpha} \cdot\left(1+\frac{R_{s}}{R_{p}}\right) T^{\alpha}+s R_{s} C}{\frac{1}{R_{p}}+s^{\alpha} \frac{T^{\alpha}}{R_{p}}+s C} \\
& \cong \frac{1+s^{\alpha} T^{\alpha}+s R_{s} C}{\frac{1}{R_{p}}+s^{\alpha} \frac{T^{\alpha}}{R_{p}}+s C}
\end{aligned}
$$

However, Orzylowski and Lewandowski [41] suggest that the CC relaxation-based SC model is likely to present a simpler implementation and analysis because it does not contain the complexity presented by the CD model. The CD model contains a binomial raised to a fractional power, $\beta$, which causes the complexity. On the other hand, the $\mathrm{CD}$ model presents a much more accurate representation of the frequency and time domain responses of the SC.

\subsection{Nonlinear Gorh's model}

A nonlinear model based on Gohr's half-porous model, as illustrated in Fig. 8, was studied in [42]. Analysis of the electrical model can be used to derive the following expressions:

$Z_{E}(s)=\sum_{k=1}^{n} Z_{E k}(s)$

$Z_{S}(s)=\sum_{k=1}^{n} Z_{S k}(s)$

and

$$
\frac{1}{Z_{1}(s)}=\sum_{k=1}^{n+1} \frac{C_{D L}(k) s}{C_{D L(k)} r_{I(k)} s+1},
$$

where $C_{D L}$ is the double-layer capacitance, $r_{I}$ is the electrode/electrolyte resistance, $Z_{E}$ is the total electrode impedance, and $Z_{S}$ is the total electrolyte impedance. 


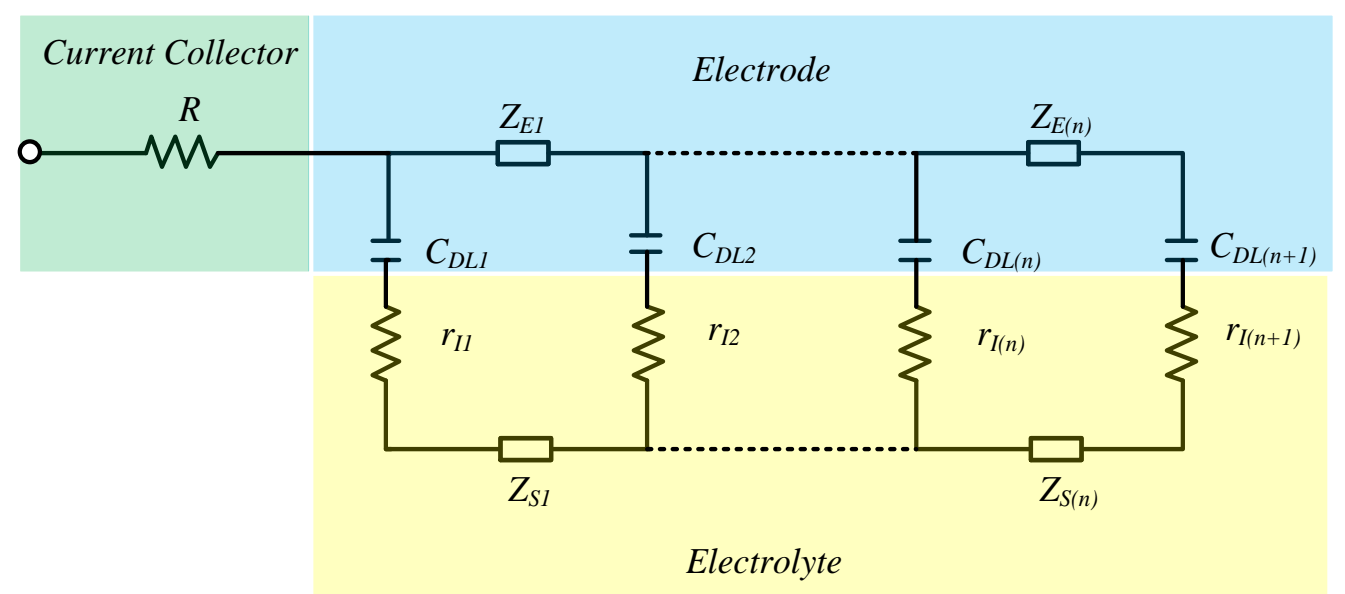

Fig. 8. Distributed half-porous model of a capacitor

The interfacial behavior of the electrode, $Z_{1}(s)$, can be approximated using a CPE impedance with fractional order $\gamma$, as follows:

$Z_{1}(s) \cong \frac{1}{C s^{\gamma}}$.

The total impedance for the half-porous model shown in Fig. 8 incorporating the rough nature of the electrode/electrolyte interface can be obtained as

$$
\begin{aligned}
& Z_{S C}(s)=R+\frac{Z_{S} Z_{E}}{\left(Z_{S}+Z_{E}\right)}+\frac{2 Z_{S} Z_{E}}{\left(Z_{S}+Z_{E}\right) C s^{2 \gamma}}+ \\
& +\frac{Z_{S}-2 Z_{S} Z_{E}+Z_{E}}{\left(\left(Z_{S}+Z_{E}\right) C s^{\gamma}\right)^{\frac{1}{2}}} \operatorname{coth}\left[\left(\left(Z_{S}+Z_{E}\right) C s^{\gamma}\right)^{\frac{1}{2}}\right] .
\end{aligned}
$$

This model can be rewritten as a function of voltage by using the Padé approximant for the hyperbolic cotangent function in the form of

$Z_{S C}(s)=K_{1}(V)+K_{2}(V) \times$

$\times \frac{\beta_{3}(V) s^{3 \gamma(V)}+\beta_{2}(V) s^{2 \gamma(V)}+\beta_{1}(V) s^{\gamma(V)}+1}{s^{4 \gamma(V)}+\alpha_{3}(V) s^{3 \gamma(V)}+\alpha_{2}(V) s^{2 \gamma(V)}+\alpha_{1}(V) s^{\gamma(V)}}$.

To transform the equation into a nonlinear form, the Taylor series approximation with integration technique is used, as in [42]. This results in the nonlinear model

$$
\left\{\begin{array}{l}
\frac{d^{\gamma} z_{1}}{d t^{\gamma}}=Z_{2} \\
\frac{d^{\gamma} z_{2}}{d t^{\gamma}}=Z_{3} \\
\frac{d^{\gamma} z_{3}}{d t^{\gamma}}=Z_{4} \\
\frac{d^{\gamma} z_{4}}{d t^{\gamma}}=-\alpha_{1}(V) Z_{2}-\alpha_{2}(V) Z_{3}-\alpha_{3}(V) Z_{4}+K_{1}(V) I
\end{array}\right.
$$

$V=Z_{1}+\beta_{1}(V) Z_{2}+\beta_{2}(V) Z_{3}+\beta_{3}(V) Z_{4}+K_{2}(V) I$

This nonlinear model's parameters can exhibit the behavior, in terms of voltage dependency, for charge and discharge very accurately. However, this model does not accurately capture the charge recovery period. As explained in [42], the SC gradually decreases in voltage and the model demonstrates a rapid decrease to a final voltage.

\subsection{Electrosorption theory-based SC model}

The change in temperature of an SC during charging-discharging phases can be credited to electrosorption. During the charging process, the ions are adsorbed into the electrode, whereas in the discharging phase, the ions are desorbed. The electrosorption phenomenon is linked to the electrode-electrolyte interface voltage, which might cause the nonlinear behavior such as self-discharge or relaxation in SCs.

The model of N. Bertrand et al. [43] is based on this phenomenon and its circuit diagram, given in Fig. 8. On the basis of the adsorption theory, the impedance at the electrolyte-electrode interface is derived to be

$Z_{1}(s)=\frac{1-k_{a d s} s^{\gamma-1}}{C s}$,

where $\gamma$ is the fractional (real) order positive value and $k_{a d s}$ is the adsorption coefficient. The fractional order signifies the characteristics of diffusion species that are adsorbed into the porous structure. Considering the electrode impedance is zero, the overall SC model described by equation (29) is based on the electrolyte-electrode impedance, as per equation (28) and the transmission line theory, 


$$
\begin{aligned}
& Z_{S C}(s)=R_{S}+\sqrt{R_{l_{-} e q} \frac{1-k_{a d s} s^{\gamma-1}}{C s}} \times \\
& \times \operatorname{coth}\left(\sqrt{\frac{R_{l_{-} e q} C s}{1-k_{a d s} s^{\gamma-1}}}\right),
\end{aligned}
$$

where $R_{l_{-} e q}$ is the equivalent transmission line resistance.

To simplify the complexity of hyperbolic cotangent function in the time domain, and for simulation purposes, a better approximation of the aforementioned model is approximated using the Taylor expansion approximation. The approximated function of the model for low-frequency regions can be given as

$Z_{S C_{-} L F}(s)=R_{s}+\frac{R_{l_{-} e q}}{3}+\frac{\left(1-k_{a d s} s^{\gamma-1}\right)}{C s}$

The high-frequency region is modeled to have an approximate impedance of

$$
\begin{aligned}
& Z_{S C_{-} L F}(s)=R_{s}+\frac{R_{l_{-} e q}}{10}+\frac{\left(1-k_{a d s} s^{\gamma-1}\right)}{C s}+ \\
& +\frac{0.233 R_{l_{-} e q} \times 2.45 \frac{\left(1-k_{a d s} s^{\gamma-1}\right)}{C s}}{0.233 R_{l_{-} e q}+2.45 \frac{\left(1-k_{a d s} s^{\gamma-1}\right)}{C s}} .
\end{aligned}
$$

However, the same low-frequency model was used for a more concise presentation in [43]. This model is then transformed into a nonlinear model by representing the equation in pseudo-state space and applying the pseudo-integration technique. This gives a nonlinear model that accounts for the charge and discharge behavior where only the parameters that denote the adsorption and desorption are different,

$$
\begin{aligned}
& \left\{\begin{array}{l}
\frac{d}{d t} V_{d l}=\frac{1}{C} I_{s c}, \\
\frac{d^{2-\gamma}}{d t^{2-\gamma}} V_{a d s}=-\frac{k_{a d s}(V)+\operatorname{sign}\left(I_{s c}\right) \Delta k_{a d s}(V)}{C} I_{s c} ;
\end{array}\right. \\
& V_{s c}=V_{d l}+V_{a d s}+\left(R_{s}+\frac{R_{l_{-} e q}}{3}\right) I_{s c} ; \\
& k_{a d s}(V)=\frac{K_{a d s}(V)+K_{d e s}(V)}{2} \Delta k_{a d s}(V)= \\
& =\frac{K_{a d s}(V)-K_{d e s}(V)}{2},
\end{aligned}
$$

where the subscripts ads, des, and $d l$ denote adsorption, desorption, and double layer, respectively.
Further, $K$ is a constant variable, and $V$ and $I$ denote voltage and current symbols, respectively.

The nonlinear behavior attributed to the electrosorption phenomenon was investigated in [43] and was found to be non-negligible. Because of this phenomenon, there is some charge transfer between the adsorbed ions and the electrodes. This charge transfer causes a rise and decrease in capacitance during the charge and discharge phases. The test, conducted on a $2000 \mathrm{~F} / 2.7 \mathrm{~V}$ SC, showed that the fractional order $\gamma$ was close to 1 , which depicted the fractional-order behavior of the SC.

\subsection{A nonlinear model SC for embedded applications}

An SC model based on the circuit given in Fig. 8 was also investigated in [44]. This type of circuit could be embedded on electronic boards, such as in calculators. The model considers the electrode impedance as zero, whereas the electrolyte impedance can be assumed to be resistors. Thus, the following equations are derived:

$$
\begin{aligned}
& z_{s(k)}=r_{e l(k)} \\
& R_{e l}=\sum_{k=1}^{n} r_{e l(k)} \\
& Z_{I}(s) \approx \frac{1}{C s^{1-\gamma}}
\end{aligned}
$$

The electrolyte-electrode interface impedance, or the constant phase impedance in this particular model, is approximated to be $Z_{\mathrm{I}}(s)$, which is slightly different than in equation (20). In this case, the total impedance of the $\mathrm{SC}$ is given through transmission line theory by

$Z_{S C}(s)=R_{s}+\left(\frac{R_{e l}}{C(s)^{1-\gamma}}\right)^{\frac{1}{2}} \operatorname{coth}\left[\left(R_{e l} C(s)^{1-\gamma}\right)^{\frac{1}{2}}\right]$.

Because of difficulties in implementing the coth function in the real time system, the Padé approximation method is used. The final form is then obtained and works accurately for frequencies ranging from $1 \mathrm{mHz}$ to $10 \mathrm{~Hz}$.

$$
\tilde{Z}_{S C}(s)=R+R_{1}+\frac{1}{C_{1} s^{1-\gamma}}+\frac{R_{2}}{R_{2} C_{2} s^{1-\gamma}+1},
$$

where the variables $\left(R_{1}, R_{2}\right)$ and $\left(C_{1}, C_{2}\right)$ are constant multiples of the parameters $R_{e l}$ and $C$, respectively, and are shown in the following equations: 


$$
\begin{aligned}
& R_{1}=\frac{R_{e l}}{10}, R_{2}=0.233 \mathrm{R}_{e l} \\
& C_{1}=C, C_{2}=1.2 C
\end{aligned}
$$

Using the same technique as in the aforementioned method, the model described in equation (35) can be transformed into a nonlinear model as

$$
\begin{aligned}
& \frac{d^{1-\gamma} z_{1}}{d t^{\gamma}}=z_{2} \frac{d^{1-\gamma} z_{2}}{d t^{\gamma}}=-\frac{1}{R_{2} C_{2}} z_{2}+\frac{1}{R_{2} C_{2} C_{1}} I \\
& V=Z_{1}+\left(C_{2} R_{2}+C_{1} R_{2}\right) z_{2}+\left(R_{s}+R_{1}\right) I
\end{aligned}
$$

This model was designed for embedded systems due to its simplicity when it comes to nonlinear model implementations. To embed the model, the fractional integrator must be approximated by an integer transmittance. This model was evaluated with a Maxwell 2000 F/2.5 V SC, which showed there was an approximate $1 \%$ relative error for a 10 A current profile and a $2 \%$ relative error for a 100 A current profile.

\subsection{Fractal stationary model}

Electrochemical impedance spectra were studied by Martynvuk and Ortigueira [45] with the help of the
Nyquist plot. An HE0120C-0027A SC was used in the experimental study with a capacitance of $120 \mathrm{~F}$ rated at $2.7 \mathrm{~V}$. Unlike the model in equation (14), which is based on two frequency ranges, a low-frequency region with $\theta=90^{\circ}$ and a high-frequency region with $\theta=45^{\circ}$ of a Nyquist plot for impedance spectrum, this model consists of three regions. These regions consist of the same high and low-frequency ranges, but a middle-frequency region, where $\theta=75^{\circ}$, is added. This model is formed from a series resistor, $R_{s}$, two capacitors, $C_{a}$ and $C_{b}$, and a fractional element, $D$, of order $\leq 2$. The transfer function derived for this model is given by equation (38), and its electrical equivalence is shown in Fig. 9. The fractional element of parameter $D$ can be realized by the general impedance converter (GIC), as shown in Fig. 10.

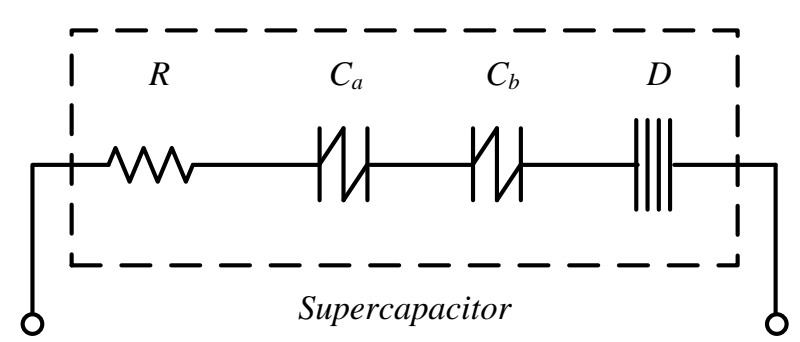

Fig. 9. The model based on three frequency regions

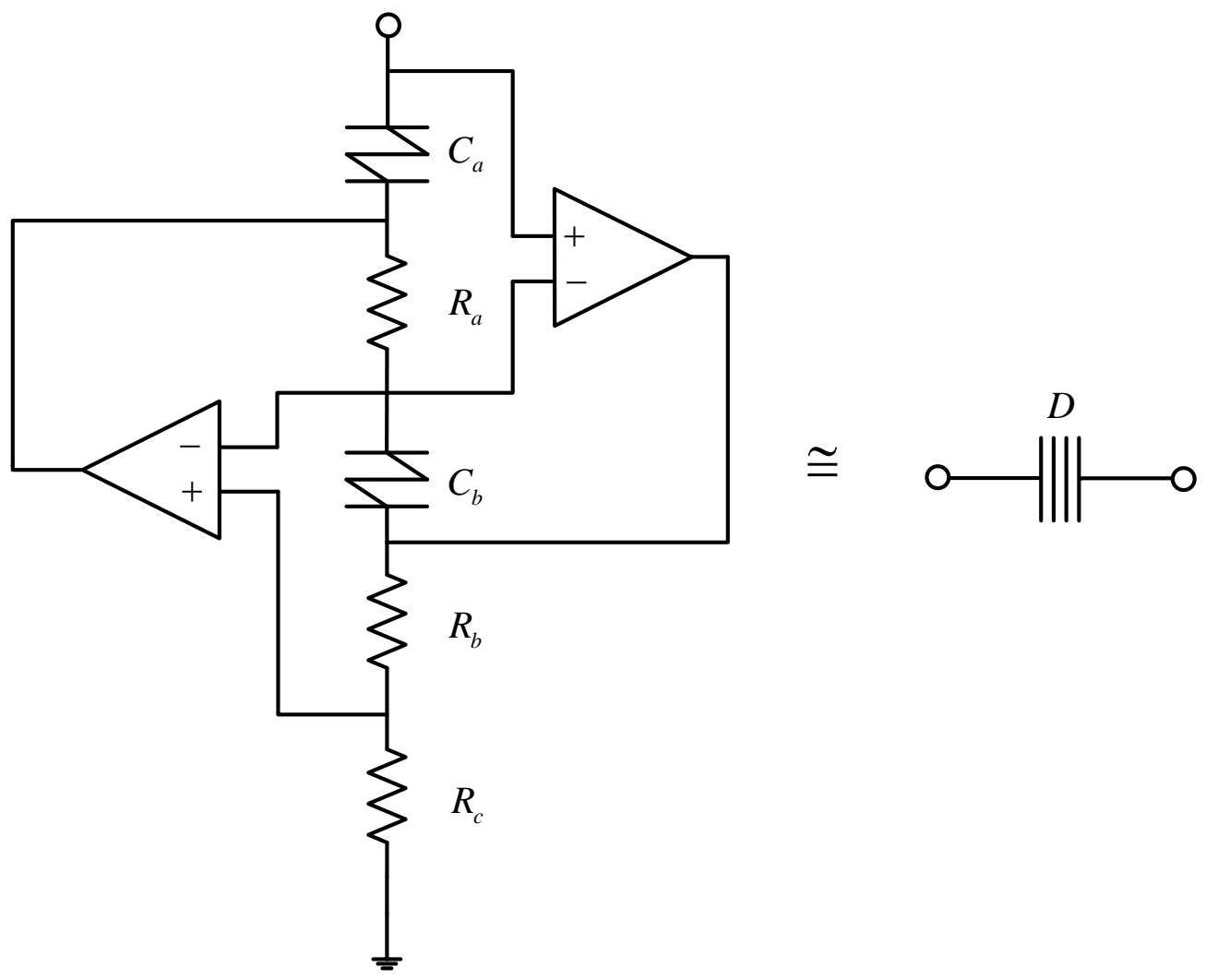

Fig. 10. Fractional-order element $D$ of the order $\alpha+\beta \leq 2$, realized by GIC 


$$
\begin{aligned}
H_{S T}(s) & =k \frac{\left[s^{\alpha}+A\right]\left[1+B s^{\beta}\right]}{s^{\alpha+\beta}}= \\
& =R+\frac{1}{s^{\alpha} C_{a}}+\frac{1}{s^{\beta} C_{b}}+\frac{1}{s^{\alpha+\beta} D} .
\end{aligned}
$$

The expression derived from Fig. 10, which represents the element, is given as

$$
\begin{aligned}
Z(s) & =\frac{\left(1 / s^{\alpha} C_{\alpha}\right)\left(1 / s^{\alpha} C_{\alpha}\right) R_{c}}{R_{a} R_{b}}= \\
& =\frac{R_{c}}{s^{\alpha+\beta} C_{a} C_{b} R_{a} R_{b}}= \\
& =\frac{1}{s^{\alpha+\beta} D},
\end{aligned}
$$

where

$$
D=\frac{C_{a} C_{b} R_{a} R_{b}}{R_{c}}
$$

The frequency model in equation (39) can easily be transformed into the time domain by performing the Laplace inverse transformation. The impulse response $\left(h_{i m p}\right)$ of transfer function (38) is given by equation (41), and equation (42) is the unit step response $\left(h_{S T}\right)$ of the system, as follows:

$$
\begin{aligned}
& h_{i m p}(t)=R \delta(t)+\frac{t^{a-1}}{C_{a} \Gamma(a)} u(t)+ \\
& +\frac{t^{b-1}}{C_{b} \Gamma(b)} u(t)+\frac{t^{(a+b)-1}}{D \Gamma(a+b)} u(t) ; \\
& h_{S T}(t)=R u(t)+\frac{t^{a}}{C_{a} \Gamma(1+a)} u(t)+ \\
& +\frac{t^{b}}{C_{b} \Gamma(1+b)} u(t)+\frac{t^{(a+b)}}{D \Gamma(1+a+b)} u(t) .
\end{aligned}
$$

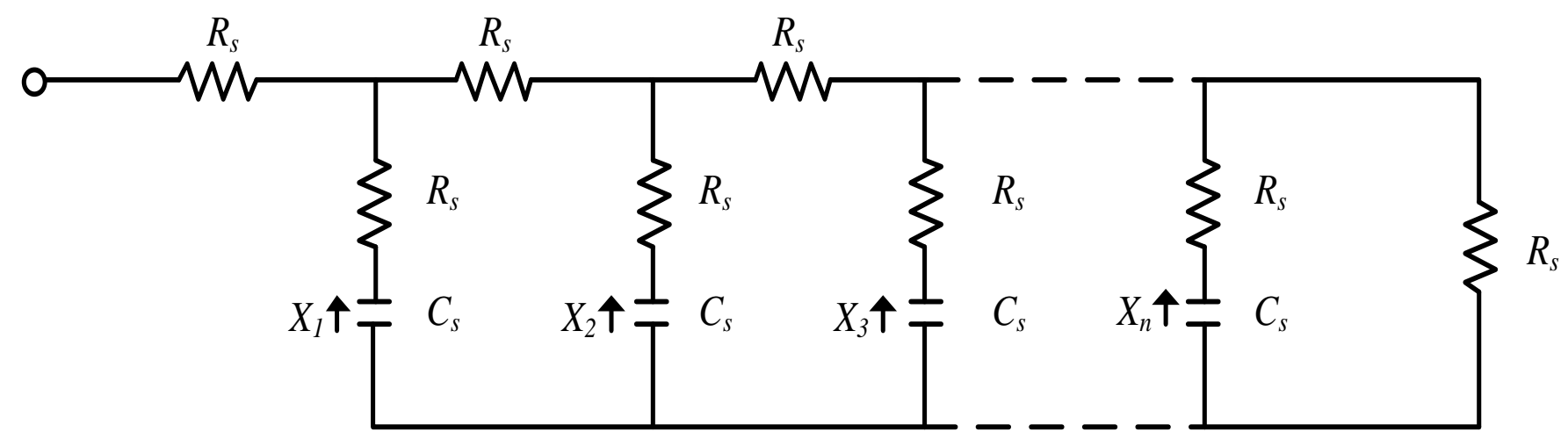

Fig.12. RC Ladder Network 
The dynamic behavior of the model in Fig. 12 can be described with a simple fractional-order differential expression in state space form as

$$
C_{s} R_{s} F \frac{d_{\alpha} x(t)}{d t_{\alpha}}=A x(t)+B u(t)
$$

where the variables $A, B$, and $F$ are the coefficient matrix; the variable $x(t)$ is a $n \times 1$ matrix; and $u(t)$ are matrices of order $n \times 1$.

Furthermore, the transfer function based on the $\mathrm{RC}$ ladder can be written as

$$
G(s)=\frac{b_{k}}{s^{\alpha}-a_{k}},
$$

where

$$
\begin{aligned}
& k=1,2,3, \ldots \ldots, n . \\
& a_{k}=\frac{4 \sin ^{2} \frac{\varphi_{k}}{2}}{C_{s} R_{s}\left(1+4 \sin ^{2} \frac{\varphi_{k}}{2}\right)} \\
& b_{k}=\frac{\sqrt{\frac{2}{n+1}} \sin \varphi k}{C_{s} R_{s}\left(1+4 \sin ^{2} \frac{\varphi_{k}}{2}\right)} \\
& \varphi_{k}=k \pi /(n+1)
\end{aligned}
$$

The larger extended RC transmission line network is more likely to capture the resistance and double-layer capacitance that extends to the depth of the porous structure of the SC. The addition of more $\mathrm{RC}$ elements adds more dynamics compared with the RC ladder network.

\subsection{Linear parameter varying-based fractional model}

Kanoun et al. [47] present porous impedance (also called CPE) using a similar structure to the one illustrated in Fig. 4. The impedance model in equation (48) is based on the unique pore model of the capacitor and is given by

$Z_{C P E}=\frac{b_{0}}{s}+b_{1} M_{0.5}(s)$.

In general, the integrator function, $M_{n}$ of order $n$, is derived by cascading elementary phase delay filter, as defined by equation (49). In this model, $n=0.5$ and can be defined in the frequency range $\left[\omega_{b}, \omega_{h}\right]$.

$$
M_{n}(s)=\omega_{b}^{-n} \prod_{i=1}^{N_{c}} \frac{1+\frac{s}{\omega_{i}}}{1+\frac{s}{\omega_{i}^{\prime}}}
$$

Function $M_{n}$ is defined through the distribution of poles and zeros as

$$
\omega_{i}=\alpha \omega_{i}^{\prime}, \omega_{i+1}^{\prime}=\eta \omega_{i}, n=\frac{\log (\alpha)}{\log (\alpha \eta)},
$$

and the recursive linked parameters, $\alpha$ and $\eta$, of the integrator are

$\alpha=\left(\frac{\omega_{h}}{\omega_{b}}\right)^{\frac{n}{N_{c}}}, \quad \eta=\left(\frac{\omega_{h}}{\omega_{b}}\right)^{\frac{1-n}{N_{c}}}$.

It is noted that such multipored models can also be described by adding two fractional integrators of order $n$ and $n / 2$. Thus, the output voltage to input current transfer impedance is given by

$Z_{C P E}(s)=\frac{b_{0}}{s}+\frac{b_{1}}{s^{n / 2}}$.

Given that the fractional integrator is based on the phase-lead filter, $P_{n}$ of order $n$ is defined by

$$
P_{n}(s)=\frac{\omega_{b}{ }^{1-n}}{s} \prod_{i=1}^{N_{c}} \frac{1+\frac{s}{\omega_{i}}}{1+\frac{s}{\omega_{i}^{\prime}}},
$$

where the complete description of the integrator $P_{n}$ is given as

$$
\begin{aligned}
& \omega_{i}=\alpha \omega_{i}^{\prime}, \omega_{i+1}^{\prime}=\eta \omega_{i}, n=1-\frac{\log (\alpha)}{\log (\alpha \eta)} \\
& \alpha=\left(\frac{\omega_{h}}{\omega_{b}}\right)^{\frac{1-n}{N_{c}}}, \quad \eta=\left(\frac{\omega_{h}}{\omega_{b}}\right)^{\frac{n}{N_{c}}}
\end{aligned}
$$

The model in equation (52) can be rewritten in terms of equations (49) and (53) as follows:

$$
Z_{C P E}=b_{0} P_{n}(s)+b_{1} M_{n / 2}(s) \text {. }
$$

Thus, this SC model is based on Fig. 4 with porous impedance defined by equations (52) and (55). The multipore description is much more accurate in terms of describing the infinity of parallel pores in the porous structures of the electrodes. Both of the models produce similar results; however, the single pore model is much more preferable in order to sim- 
ulate the output voltage time response when supplied with charging current.

\subsection{Flexible SC model}

A more generalized network was proposed by Prasad et al. [48]. Their model offered to ease the difficulty of selecting an optimal model for an SC when analyzing/designing systems using SCs. The proposed model is illustrated in Fig. 13.

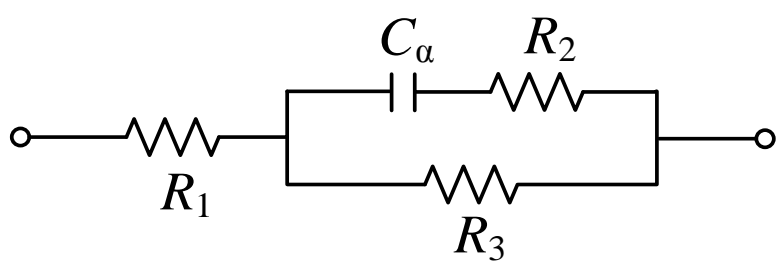

Fig. 13. Flexible SC model

Impedance for this model can be described by

$$
Z_{S C}(s)=\frac{C_{\alpha} s^{\alpha}\left(\frac{R_{1} R_{2}}{R_{3}}+R_{1}+R_{2}\right)+\frac{R_{1}}{R_{3}}+1}{\frac{1}{R_{3}}+C_{\alpha} s^{\alpha}\left(\frac{R_{2}}{R_{3}}+1\right)}
$$

Using the charging circuit given in Fig. 4 with the SC model in Fig. 13, the charging equation in Laplacian form is derived as

$$
\begin{aligned}
& V_{o}(s)= \\
& =\frac{\left[\begin{array}{l}
V_{i n}(s)+V_{i n}(s) \frac{R_{1}}{R_{3}}+ \\
+C s^{\alpha}\left(V_{i n}(s) R_{2}+V_{i n}(s) \frac{R_{1} R_{2}}{R_{3}}+V_{i n}(s) R_{1}\right)+ \\
+s^{\alpha-1}(C R v(0))
\end{array}\right]}{\left[\begin{array}{l}
\left(1+\frac{R_{1}}{R_{3}}+\frac{R}{R_{3}}\right)+ \\
+C s^{\alpha}\left(R_{2}+\frac{R_{1} R_{2}}{R_{3}}+\frac{R R_{2}}{R_{3}}+R_{1}+R\right)
\end{array}\right]}
\end{aligned}
$$

The time domain step response with a magnitude $v_{\text {step }}$, based on the Mittag-Leffler function in equation (3), is given as

$$
v_{s c}(t)=\left[\frac{v_{\text {step }}(t)+v_{\text {step }}(t) \frac{R_{1}}{R_{3}}}{C\left(R_{2}+\frac{R_{1} R_{2}}{R_{3}}+\frac{R R_{2}}{R_{3}}+R_{1}+R\right)}\right] t^{\alpha} \mathrm{E}_{\alpha, \alpha+1}\left(-W t^{\alpha}\right)+
$$

$$
\begin{aligned}
& +\left[\frac{v_{\text {step }}(t) R_{2}+v_{\text {step }}(t) \frac{R_{1} R_{2}}{R_{3}}+v_{\text {step }}(t) R_{1}+R v(0)}{R_{2}+\frac{R_{1} R_{2}}{R_{3}}+\frac{R R_{2}}{R_{3}}+R_{1}+R}\right] \times \\
& \times \mathrm{E}_{\alpha, 1}\left(-W t^{\alpha}\right)
\end{aligned}
$$

where

$$
W=\frac{1+R_{1} / R_{3}+R / R_{3}}{C\left(R_{2}+R_{1} R_{2} / R_{3}+R R_{2} / R_{3}+R_{1}+R\right)} .
$$

For the discharge equation, the input voltage value could be set to zero, indicating no voltage supply.

The usefulness of this model was demonstrated on three different branded SCs, each containing three different capacitance values. This model took the most optimal form based on the parameter optimization that could be achieved from the model in Fig. 13. The study found that the nine SCs demonstrated a total of four sub-models of Fig. 13: 1) only fractional capacitor model, 2) simple porous model, 3) RC parallel network, and 4) RC parallel network with no $R_{s}$. This model helps in designing systems incorporating SC that require modeling and may help improve accuracy.

\subsection{Summary of fractional SC models}

The fractional-order transfer function has been extensively utilized in SC modeling. Further, interest in using fractional calculus-based modeling has been increasing because of the increase of various electrical applications. Examples of these applications include modeling of radio frequency and microwave designs [49], modeling inductor coil loses [50], expanding the versatility and freedom of electrical circuits [51, 52], and generalizing the Smith chart in fractional domain to plot and match the radio frequency and microwave regime fractional impedances [53].

From various studies, it has been concluded that SCs exhibit fractional behavior due to anomalous diffusion $[38,43]$ and the dielectric relaxation phenomenon [41-45, 54]. Non-integer orders allow for one more degree of freedom than integer orders, resulting in better approximation of the complex system dynamics. In other words, the non-integer order of a transfer function can describe a system's dynamics with greater accuracy than the higher-order integer. However, the modeling of the implemented cir- 
cuit is less complex when using higher-order integer transfer functions.

Table 1. Summary table

\begin{tabular}{|c|c|}
\hline Model & Remark \\
\hline 1. Simple porous model & $\begin{array}{l}\text { - Simple to use in analysis. Less } \\
\text { complex in nature. }\end{array}$ \\
\hline $\begin{array}{l}\text { 2. Poles and zeros } \\
\text { model }\end{array}$ & $\begin{array}{l}\text { - Appropriate for frequency domain plot } \\
\text { analysis, such as Nyquist plot and } \\
\text { Bode diagrams. }\end{array}$ \\
\hline 3. Structural model & $\begin{array}{l}\text { Introduces a complex set of constant } \\
\text { phase elements, which captures more } \\
\text { dynamics. }\end{array}$ \\
\hline 4. $\mathrm{RC}$ parallel model & $\begin{array}{l}\text { Slightly better than the simple porous } \\
\text { model because dynamic changes due to } \\
\text { leakage current are accounted for. }\end{array}$ \\
\hline $\begin{array}{l}\text { 5. Nonlinear Gohr's } \\
\text { Model }\end{array}$ & $\begin{array}{l}\text { - Nonlinear behavior is handled better } \\
\text { using this. }\end{array}$ \\
\hline $\begin{array}{l}\text { 6. Electrosorption theo- } \\
\text { ry-based SC model }\end{array}$ & $\begin{array}{l}\text { - Accounts for the nonlinearity induced } \\
\text { because of electrosorption phenome- } \\
\text { non. }\end{array}$ \\
\hline $\begin{array}{l}\text { 7. A nonlinear model for } \\
\text { embed applications }\end{array}$ & $\begin{array}{l}\text { Designed for embedded system appli- } \\
\text { cations due to its simplicity. }\end{array}$ \\
\hline $\begin{array}{l}\text { 8. Fractal stationary } \\
\text { model }\end{array}$ & $\begin{array}{l}\text { - Similar to the simple porous model but } \\
\text { more dynamic in nature because it has } \\
\text { a couple of fractional capacitances and } \\
\text { a fractal element in series with a resis- } \\
\text { tor. For frequency analysis, it covers a } \\
\text { much wider range of frequencies. }\end{array}$ \\
\hline $\begin{array}{l}\text { 9. RC ladder network- } \\
\text { based model }\end{array}$ & $\begin{array}{l}\text { - More dynamic in nature compared with } \\
\text { the simple porous and RC parallel } \\
\text { models. }\end{array}$ \\
\hline $\begin{array}{l}\text { 10. Modeling based on } \\
\text { fractional integrators }\end{array}$ & $\begin{array}{l}\text { Describes the behavior of an elec- } \\
\text { trode's porous structure more accurate- } \\
\text { ly. }\end{array}$ \\
\hline 11. Flexible SC model & $\begin{array}{l}\text { A more generalized model, it eases the } \\
\text { need of selecting an optimal model } \\
\text { from the vast range available. }\end{array}$ \\
\hline
\end{tabular}

\section{References}

[1] Yang Z., Chen C.Y., Chang H.T. Supercapacitors incorporating hollow cobalt sulfide hexagonal nanosheets. Journal of Power Sources, 2011, vol.196, no. 18, pp. 7874-7877. doi:10.1016/j.jpowsour.2011.03.072.

[2] Zhu Y., Murali S., Stoller M.D., Ganesh K.J., Cai W., Ferreira P.J., Pirkle A., Wallace R.M., Cychosz K.A., Thommes M., Su, D., Stach E.A., Ruoff R.S. Carbonbased supercapacitors produced by activation of graphene. Science, 2011, vol. 332, no. 6037, pp. 15371541. doi:10.1126/science. 1200770.

[3] Stejskal J. Polymers of phenylenediamines. Progress in Polymer Science, 2015, vol. 41, no. C, pp. 1-31. doi:10.1016/j.progpolymsci.2014.10.007.

[4] Javaid A. Activated carbon fiber for energy storage, in: Activated Carbon Fiber and Textiles. Amsterdam, Elsevier, 2017, pp. 281-303. doi:10.1016/b9780-08-1006603.00011-0.

[5] Conway B. E. Electrochemical Supercapacitors: Scientific Fundamentals and Technological Applications. US, Springer, 1999. doi:10.1007/978-1-4757-3058-6.
Fractional calculus-based dynamic models are usually descriptions over a wider frequency range due to its advantages of long memory characteristics. They also capture transient state behaviors, which arise because of the dielectric relaxation. A summary of all the fractional models analyzed is given in Table 1.

\section{Conclusions}

SCs are commonly used in power supplies, renewable energy applications, electric vehicles and other applications. With so many applications, SC models in various electrical circuits are very critical and important to consider in order to successfully control the charging and discharging of energy storage devices.

This paper presented a survey of recent literature pertaining to fractional modeling of SCs. Fractional calculus has been vastly used in biochemistry over years, and it is now being utilized successfully in engineering fields. First, a brief introduction on various types of SCs with respect to internal structure was described. Then, this paper presented a summary of fractional models that are practically accurate as well as feasible to incorporate in analysis and to control power in applications. The survey depicted various models that attempt to capture the dynamics of SCs while maintaining meaningful parameters. Additionally, it showed how fractional order is being utilized in impedance modeling effectively for electrical applications.

[6] Wang Y., Xia, Y. Recent progress in supercapacitors: From materials design to system construction. Advanced Materials, 2013, vol. 25, no. 37, pp. 5336-5342. doi:10.1002/adma.201301932.

[7] Cao J., Emadi A. A new battery/ultracapacitor hybrid energy storage system for electric, hybrid, and plug-in hybrid electric vehicles. IEEE Transactions on Power Electronics, 2012, vol. 27, no. 1, pp. 122-132. doi:10.1109/tpel.2011.2151206.

[8] Voorden A.M. van, Elizondo L.M.R., Paap G.C., Verboomen J., Sluis van der L. The application of super capacitors to relieve battery storage systems in autonomous renewable energy systems. IEEE Lausanne Power Tech, 2007, pp. 479-484. doi:10.1109/pct.2007.4538364.

[9] Goodenough J.B., Abruna H.D., Buchanan M.V. Basic research needs for electrical energy storage. Report of the basic energy sciences workshop on electrical energy storage, 2007, vol. 186. doi:10.2172/935429.

[10] Podlubny I. Fractional-order systems and $\mathrm{PI}^{\lambda} \mathrm{D}^{\mu}$ controllers. IEEE Transactions on Automatic Control, 1999, vol. 44, no. 1, pp. 208-214. doi:10.1109/9.739144.

[11] Magin R.L. Fractional calculus models of complex dynamics in biological tissues. Computers \& Mathematics 
with Applications, 2010, vol. 59, no. 5, pp. 1586-1593. doi:10.1016/j.camwa.2009.08.039.

[12] Zhao C., Xue D., Chen Y. A fractional order PID tuning algorithm for a class of fractional order plants. IEEE International Conference Mechatronics and Automation, 2005, pp. 216-221. doi:10.1109/icma.2005.1626550.

[13] Saadatmandi A., Dehghan M. A new operational matrix for solving fractional-order differential equations. Computers \& Mathematics with Applications, 2010, vol. 59, no. 3, pp. 1326-1336. doi:10.1016/j.camwa.2009.07.006.

[14] van den Eeden A., Sluyters J., van Lenthe J. The metal side of the electrical double layer at the metal/electrolyte interface. Journal of Electroanalytical Chemistry and Interfacial Electrochemistry, 1984, vol. 171, no. 1-2, pp. 195-217. doi:10.1016/0022-0728(84)80114-x.

[15] Sharma P., Bhatti T. A review on electrochemical double-layer capacitors. Energy Conversion and Management, 2010, vol. 51, no. 12, pp. 2901-2912. doi:10.1016/j.enconman.2010.06.031.

[16] Becker H.I. Low voltage electrolytic capacitor. US Patent 2,800,616, issued Jul. 231957.

[17] Sharma H., Haque A., Jaffery Z.A. Solar energy harvesting wireless sensor network nodes: A survey. Journal of Renewable and Sustainable Energy, 2018, vol. 10, no. 2, pp. 023704. doi:10.1063/1.5006619.

[18] Bose S., Kuila T., Mishra, A.K., Rajasekar, R., Kim, N.H., Lee, J.H. Carbon-based nanostructured materials and their composites as supercapacitor electrodes. Journal of Materials Chemistry, 2012, vol. 22, no. 3, pp. 767-784. doi:10.1039/c1jm14468e.

[19] Xiong G., Meng C., Reifenberger R.G., Irazoqui P.P., Fisher T.S. A review of graphene-based electrochemical microsupercapacitors. Electroanalysis, 2013, vol. 26, no. 1, pp. 30-51. doi:10.1002/elan.201300238.

[20] Vidhyadharan B., Zain, N.K.M., Misnon I.I., Aziz R.A., Ismail J., Yusoff M.M., Jose, R. High performance supercapacitor electrodes from electrospun nickel oxide nanowires. Journal of Alloys and Compounds, 2014, vol. 610, pp. 143-150. doi:10.1016/j.jallcom.2014.04.211.

[21] Winter M., Brodd R.J. What are batteries, fuel cells, and supercapacitors?. Chemical Reviews, 2004, vol. 104, no. 10, pp. 4245-4270. doi:10.1021/cr020730k.

[22] Aricò A.S., Bruce P., Scrosati B., Tarascon J.M., van Schalkwijk W. Nanostructured materials for advanced energy conversion and storage devices. Nature Materials, 2005, vol. 4, no. 5, pp. 366-377. doi:10.1038/nmat1368.

[23] Zhang L., Hu X., Wang Z., Sun F., Dorrell D.G. A review of supercapacitor modeling, estimation, and applications: A control/management perspective. Renewable and Sustainable Energy Reviews, 2018, vol. 81, pp. 1868-1878. doi:10.1016/j.rser.2017.05.283.

[24] Xu J., Kato K. Formation of tribochemical layer of ceramics sliding in water and its role for low friction. Wear, 2000, vol. 245, no. 1-2, pp. 61-75. doi:10.1016/s0043-1648(00)00466-x.

[25] Ermolina I., Morgan H. The electrokinetic properties of latex particles: comparison of electrophoresis and dielectrophoresis. Journal of Colloid and Interface Science, 2005, vol. 285, no. 1, pp. 419-428. doi:10.1016/j.jcis.2004.11.003.

[26] Xu Z.P., Jin Y., Liu S., Hao Z.P., Lu G.Q.M. Surface charging of layered double hydroxides during dynamic interactions of anions at the interfaces. Journal of Colloid and Interface Science, 2008, vol. 326, no. 2, pp. 522-529. doi:10.1016/j.jcis.2008.06.062.

[27] Rica R.A., Ziano R., Salerno D., Mantegazza F., Bazant M.Z., Brogioli D. Electro-diffusion of ions in porous electrodes for capacitive extraction of renewable energy from salinity differences. Electrochimica Acta, 2013, vol. 92, pp. 304-314 doi:10.1016/j.electacta.2013.01.063.

[28] Simon P., Gogotsi Y. Materials for electrochemical capacitors. Nature Materials, 2008, vol. 7, no. 11, pp. 845-854. doi:10.1038/nmat2297.

[29] Freeborn T.J., Maundy B., Elwakil A.S. Measurement of supercapacitor fractional-order model parameters from voltage-excited step response. IEEE Journal on Emerging and Selected Topics in Circuits and Systems, 2013, vol. 3, no. 3, pp. 367. doi:10.1109/JETCAS.2013.2271433.

[30] Elwakil A.S., Allagui A., Freeborn T.J., Maundy B.J. Further experimental evidence of the fractional-order energy equation in supercapacitors. $A E U$ - International Journal of Electronics and Communications, 2017, vol. 78, pp. 209-212. doi:10.1016/j.aeue.2017.03.027.

[31] Kopka R. Estimation of supercapacitor energy storage based on fractional differential equations. Nanoscale Research Letters, 2017, vol. 12, no. 1, pp. 636. doi:10.1186/s11671-017-2396-y.

[32] Quintana J.J., Ramos A., Nuez I. Identification of the fractional impedance of ultracapacitors. IFAC Proceedings Volumes, 2006, vol. 39, no. 11, pp. 432-436. doi:10.3182/20060719-3-PT-4902.00073.

[33] Allagui A., Freeborn T.J., Elwakil A.S., Maundy B.J. Reevaluation of performance of electric double-layer capacitors from constant-current charge/discharge and cyclic voltammetry. Scientific Reports, 2016, vol. 6, doi:10.1038/srep38568.

[34] Kopka R., Tarczyński W. A fractional model of supercapacitors for use in energy storage systems of next-generation shipboard electrical networks. Journal of Marine Engineering \& Technology, 2017, vol. 16, no. 4, pp. 200-208. doi:10.1080/20464177.2017.1386818.

[35] Sarwas G. Modelling and control of systems with ultracapacitors using fractional order calculus, Ph.D., The Institute of Control and Industrial Electronics, 2013.

[36] Dzielinski A., Sarwas G., Sierociuk D. Time domain validation of ultracapacitor fractional order model. 49th IEEE Conference on Decision and Control (CDC), 2010, pp. 3730-3735. doi:10.1109/CDC.2010.5717093.

[37] Kanoun H., Gabano J.D., Poinot T. Fractional modeling of ultracapacitors dynamic behavior. IFAC Proceedings Volumes, 2011, vol. 44, no. 1, pp. 13978-13983. doi:10.3182/20110828-6-it-1002.00731.

[38] Martin R., Quintana J.J., Ramos A., de la Nuez, I. Modeling electrochemical double layer capacitor, from classical to fractional impedance. The 14th IEEE Mediterranean Electrotechnical Conference, 2008. doi:10.1109/MELCON.2008.4618411.

[39] Spyker R.L., Nelms R.M. Classical equivalent circuit parameters for a double-layer capacitor. IEEE Transactions on Aerospace and Electronic Systems, 2000, vol. 36, no. 3, pp. 829-836. doi:10.1109/7.869502. 
[40] Quintana J.J., Ramos A., Nuez I. Modeling of an EDLC with fractional transfer functions using mittag-leffler equations. Mathematical Problems in Engineering, 2013, pp. 1-7. doi:10.1155/2013/807034.

[41] Orzyłowski M., Lewandowski M. Computer modeling of supercapacitor with cole-cole relaxation model. Journal of Applied Computer Science Methods, 2013, vol. 5, no. 2, pp. 105-121.

[42] Bertrand N., Sabatier J., Briat O., Vinassa J.M. Fractional non-linear modelling of ultracapacitors. Communications in Nonlinear Science and Numerical Simulation, 2010, vol. 15, no. 5, pp. 1327-1337. doi:10.1016/j.cnsns.2009.05.066.

[43] Bertrand N., Sabatier J., Briat O., Vinassa J.M. Electrosorption phenomena taken into account in a fractional model of supercapacitor. IFAC Proceedings Volumes, 2013, vol. 46, no. 1, pp. 254-259. doi:10.3182/20130204-3-FR-4032.00184.

[44] Ber N., Sabatier J., Briat O., Vinassa J.M. Embedded fractional nonlinear supercapacitor model and its parametric estimation method. IEEE Transactions on Industrial Electronics, 2010, vol. 57, no. 12, pp. 3991-4000. doi:10.1109/tie.2010.2076307.

[45] Martynyuk V., Ortigueira M. Fractional model of an electrochemical capacitor. Signal Processing, 2015, vol. 107, pp. 355-360. doi:10.1016/j.sigpro.2014.02.021.

[46] Mitkowski W., Skruch, P. Fractional-order models of the supercapacitors in the form of RC ladder networks. Bulletin of the Polish Academy of Sciences: Technical Sciences, 2013, vol. 61, no. 3, pp. 581-587. doi:10.2478/bpasts-2013-0059.

[47] Kanoun H., Gabano J.D., Poinot T. Comparison of two LPV fractional models used for ultracapacitor identification. IFAC Proceedings Volumes, 2013, vol. 46, no. 1, pp. 272-277. doi:10.3182/20130204-3-fr-4032.00045.
[48] Prasad R., Kothari K., Mehta U. Flexible fractional supercapacitor model analyzed in time domain. IEEE Access, 2019, vol. 7, pp. 122626-122633. doi:10.1109/ACCESS.2019.2938543

[49] Radwan A.G., Shamim A., Salama K.N. Theory of fractional order elements based impedance matching networks. IEEE Microwave and Wireless Components Letters, 2011, vol. 21, no. 3, pp. 120-122. doi:10.1109/lmwc.2010.2103051.

[50] Schäfer I., Krüger K. Modelling of lossy coils using fractional derivatives. Journal of Physics D: Applied Physics, 2008, vol. 41, no. 4, pp. 045001. doi:10.1088/0022-3727/41/4/045001.

[51] Radwan A.G., Soliman A.M., Elwakil A.S. Design equations for fractional-order sinusoidal oscillators: Four practical circuit examples. International Journal of Circuit Theory and Applications, 2008, vol. 36, no. 4, pp. 473-492. doi:10.1002/cta.453.

[52] Radwan A.G., Salama K.N. Fractional-order RC and RL circuits. Circuits, Systems, and Signal Processing, 2012, vol. 31, no. 6, pp. 1901-1915. doi:10.1007/s00034-0129432-z.

[53] Shamim A., Radwan A.G., Salama,K.N. Fractional smith chart theory. IEEE Microwave and Wireless Components Letters, 2011, vol. 21, no. 3, pp. 117-119. doi:10.1109/lmwc.2010.2098861.

[54] Freeborn T.J., Maundy B., Elwakil A.S. Fractional-order models of supercapacitors, batteries and fuel cells: a survey. Materials for Renewable and Sustainable Energy, 2015, vol. 4, no. 3, pp. 9. doi:10.1007/s40243-0150052-y.

Received: December 12, 2019 